\title{
The need for quality improvement in diagnosing pregnancy induced hypertension in Sri Lanka
}

\author{
S. Prathapan ${ }^{1}$, P. Fonseka ${ }^{2}$, G. Lindmark $^{3}$, R.Prathapan ${ }^{4}$, A. Lokubalasooriya ${ }^{5}$
}

${ }^{1}$ Senior Lecturer, ${ }^{2}$ Professor, Department of Community Medicine, Faculty of Medical Sciences, University of Sri Jayewardenepura, Nugegoda, Sri Lanka. ${ }^{3}$ Professor, Department of International Maternal and Child Health, University Hospital, Uppsala, Sweden. ${ }^{4}$ Consultant Obstetrician and Gynecologist, District Hospital Nuwera Eliya, Sri Lanka. ${ }^{5}$ Consultant Community Physician, Family Health Bureau, Ministry of Health, Sri Lanka.

\begin{abstract}
Sri Lanka has shown relatively good maternal outcome indicators for a developing country. However, high maternal deaths from pregnancy induced hypertension and pre-eclamptic toxemia raise questions about the quality of detection and treatment at field antenatal clinics, which is the primary care setting for pregnant women. The objective of the study was to assess the quality of facilities and services provided at the field antenatal clinics to diagnose pregnancy induced hypertension or pre-eclamptic toxemia. It was a cross-sectional study. This study was set in field antenatal clinics and was conducted in two stages based on the Lot Quality Assurance Sampling method. In the first stage 55 antenatal clinics were selected from 11 Medical officers of Health areas, and in the second stage 275 pregnant women were recruited from these 55 clinics. Quality of services and quality of facilities were assessed using observation checklists. The quality of facilities was better than the quality of services in the Colombo district. The quality of facilities was acceptable in all areas other than for the presence of the Medical Officer. The quality of services was unacceptable in all areas for history taking and examination. Investigation for urine albumin was also unacceptable in all the areas. The sensitivity for measuring the systolic blood pressure and the diastolic blood pressure were $57 \%(95 \% \mathrm{CI}: 47.4 \%-66.8 \%)$ and $16.7 \%$ (95\% CI: $9.4 \%-24 \%)$ respectively. Urgent steps should be taken to improve the quality of care in the substandard areas to reduce the leading cause of maternal mortality in Sri Lanka.
\end{abstract}

Keywords: Antenatal clinics, Maternal health, Pre-eclamptic toxemia, Pregnancy induced hypertension, Sri Lanka.

\section{Introduction}

Pregnancy-induced hypertension $(\mathrm{PIH})$ or pre-eclamptic toxemia (PET) is a major cause of maternal and perinatal mortality and morbidity worldwide. ${ }^{1}$ From the early postindependence period Sri Lanka saw a decline (6.3 per 1000 maternal deaths in 1948 and 0.8 per 1000 maternal deaths in 1977) in the maternal mortality rate (MMR). In the last 20 years, from 1990 to 2010 , the MMR further reduced from 85 per 100,000 maternal deaths to 35 per 100,000 maternal deaths. ${ }^{2}$ As Sri Lanka now targets towards a single digit in the maternal mortality ratio, there is an urgent need to reduce our maternal deaths further. ${ }^{3}$

Maternal health care services in Sri Lanka are delivered to the pregnant women at the field antenatal clinics. In each district there are many Medical Officers of Health (MOH) areas, and for each area the primary health care team under the leadership of a $\mathrm{MOH}$ plays an important role in providing maternal care. The focus on maternal care has been on outcome indicators in the last few decades and Sri Lanka has a clear picture of what is happening in terms of outcome indicators for maternal care. Further, $98 \%$ of pregnant women attend field antenatal clinics and more than $80 \%$ visit the clinics at four or more occasions. ${ }^{4,5}$

In spite the excellent outcome indicators for more than

\section{Practice Points}

- High maternal deaths from pregnancy induced hypertension and pre-eclamptic toxemia raise questions about the quality of detection and treatment at field antenatal clinics.

- The quality of facilities was acceptable in all areas in the Colombo District other than for the presence of the Medical Officer.

- The quality of services was unacceptable in all areas in the Colombo District for history taking, examination and investigation for urine albumin.

- The sensitivity for measuring the SBP and the DBP were $57 \%(95 \%$ CI: $47.4 \%-66.8 \%)$ and 16.7\% (95\% CI: 9.4\%-24\%) respectively.

- Urgent steps should be taken to improve the quality of care in the substandard areas to reduce the leading cause of maternal mortality in Sri Lanka.

Correspondence: Dr. Shamini Prathapan, Department of Community Medicine, Faculty of Medical Sciences, University of Sri Jayewardenepura, Nugegoda, Sri Lanka. Email : drpbshamini@yahoo.com.

South East Asia Journal of Public Health 2012;2(2):55-60.C 2012 Prathapan et al., publisher and licensee Public Health Foundation Bangladesh. This is an Open Access article which permits unrestricted non-commercial use, provided the original work is properly cited. 
two decades, PIH has been one of the leading causes of deaths in Sri Lanka. Since 2001, maternal deaths due to PIH have ranged from $25.4 \%$ to $14.9 \% .{ }^{4}$ In the year 2007, the PIH-specific maternal mortality ratio was 3.9/100,000 live births. ${ }^{3}$ In developed countries all hypertensive related disorders only represent $16 \%$ of all maternal deaths. ${ }^{6}$

Studies conducted during the antenatal period have stressed the quality of risk factor screening during the antenatal period. ${ }^{7}$ Early detection of the disorder is a crucial element in the prevention of pre-eclamptic mortality. ${ }^{8}$ It has been shown that quality antenatal care for early detection of high blood pressure and proteinuria, would help reduce PIH specific mortality ratio by $65 \%{ }^{9}$

It is also well known that substandard care has an influence on maternal deaths. Studies reveal that a significantly higher proportion of women $(81.3 \%)$ receive either no or inadequate quality antenatal care. ${ }^{10}$ Lower figures were reported in Canada (15.7\%). ${ }^{11}$ Studies have also shown that there was an inverse relationship between blood pressure measurement and the incidence of eclampsia and thus stress the benefits of early detection of PIH. ${ }^{10,12}$ However, on an average, $70 \%$ of the maternal care delivered to the Sri Lankan women with maternal deaths has been suboptimal. ${ }^{3}$ Thus, improving the detection rate of PIH, could help Sri Lanka in reducing maternal mortality to a single digit.

Thus the aim of this study was to assess the quality of antenatal care in diagnosing PIH/PET in the field antenatal clinics. In accordance with Donabedian's definition of quality, the study sought to assess the facilities (structure) and services (process) of field antenatal clinics in the Colombo district in diagnosing women with $\mathrm{PIH}^{13}$

\section{Materials and methods}

A cross-sectional study design was used to evaluate the quality of facilities and services pertaining to diagnosis of PIH/PET in the year 2009. The quality study was performed over a period of two months.

\section{Study sample and sample size}

Colombo district is one of the 24 districts in Sri Lanka. The district is divided into $13 \mathrm{MOH}$ areas and in each $\mathrm{MOH}$ area the pregnant woman attends the nearest antenatal clinic. Data were collected in two stages. In the first stage, all $\mathrm{MOH}$ areas other than the Borelsgamuwa $\mathrm{MOH}$ area (which is under the University of Sri Jayewardenepura) and the Pitta Kotte $\mathrm{MOH}$ area (which is under the University of Colombo) were included, so that in total $11 \mathrm{MOH}$ areas $(85 \%)$ were included. These areas were excluded as some of the service providers are from the University.

Lot Quality Assurance Sampling (LQAS) method was used as a sampling technique (Figure 1). The LQAS been used commonly to assess the program performance. ${ }^{14}$ Analysis of LQAS is quick and easy. It helps to aggregate the overall estimate, and identify the areas with substandard care. In each of the $11 \mathrm{MOH}$ areas, using the LQAS method, assuming a $75 \%$ test value and $20 \%$ anticipated value, at 5\% significance level with $90 \%$ power, five field antenatal clinics $(\mathrm{n}=55 ; 41 \%)$ were randomly selected. ${ }^{15}$ This fulfilled the recommendation to include at least $25 \%$ of the healthcare institutions in the area when assessing quality of care. ${ }^{16,17}$ The decision rule for the quality of facilities of field antenatal clinics was set at $5: 2 .{ }^{15}$

In the second stage, the sampling unit was pregnant women attending the clinics in their second or third trimester. According to the LQAS method, at least five women from each of the selected clinics in the first stage were sampled. Women in their second or third trimester were observed at the consultation room ( 25 women per $\mathrm{MOH}$ area; $\mathrm{n}=275$ ) and in the urine investigation area ( 25 women per $\mathrm{MOH}$ area; $\mathrm{n}=275$ ) to assess the quality of services of these clinics and the decision rule was set at $25: 16 .^{18}$

\section{Observations for quality of facilities}

Before the clinic services began, an observation checklist (Quality of Facilities in the Field Antenatal Clinic checklist) was used to assess the availability of facilities for diagnosis of PIH/PET. ${ }^{19}$ The checklist, based on national guidelines, included the presence of qualified $\mathrm{MOH}$, and equipments such as the sphygmomanometer and the stethoscope and the facilities to assess Albumin in Urine.

\section{Observations for quality of services}

According to the national policy all women attending the clinics should be investigated for urine albumin and be examined by the $\mathrm{MOH}$, irrespective of the period of gestation. Two female research assistants, who had completed their MBBS degree and who were awaiting their appointment as doctors were stationed in the consultation room with the $\mathrm{MOH}$ to observe the interaction with the pregnant woman with respect to diagnosing $\mathrm{PIH} / \mathrm{PET}$ and another research assistant was assigned with the healthcare workers to observe urine investigation for albumin. To assess the quality of services in investigation of albumin in urine, the observer used the checklist (Quality of services in the Field Antenatal clinic checklist) to note down the observations of the procedure. $^{19}$

Using the observation guidelines the observer in the consultation room observed the following:

- Risk factor assessment in history: age, parity, pregnancy interval, family history of pre-eclampsia, previous history of pre-eclampsia, pre-existing hypertension were considered and a history taken was considered only if all six components were inquired. $^{20,21}$

- Examination of the woman: ankle edema and/or swelling of hands or face

- Blood pressure measurement according to standards

- All findings were conveyed to the woman. 


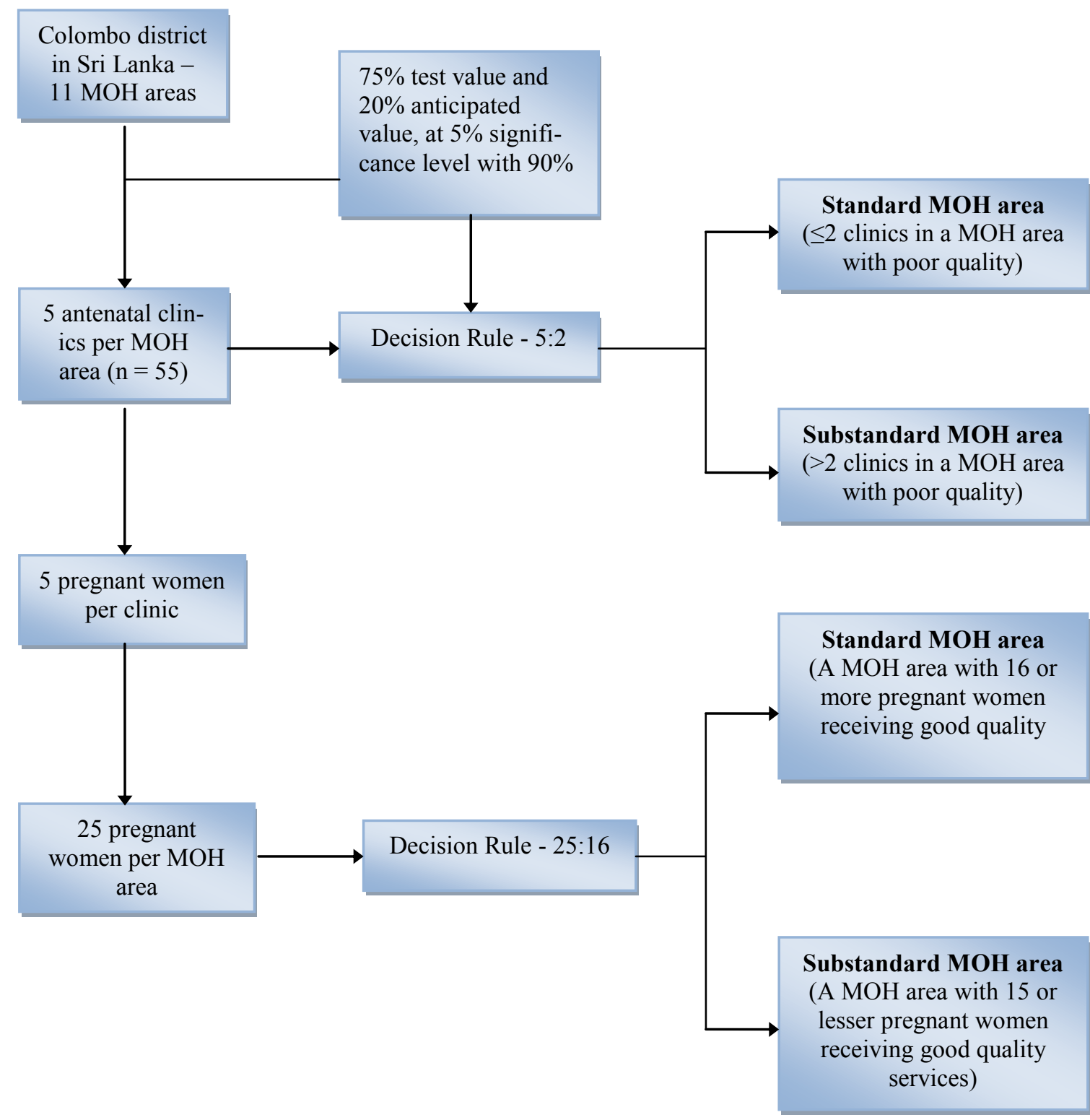

Figure 1: Flow diagram for Lot Quality Assurance Sampling

\section{Validity of the blood pressure measurement}

On exit from the consultation room, the principal researcher measured the blood pressure of all 275 women, three times at one minute intervals, using a mercury sphygmomanometer. The average of these three readings was recorded as the woman's blood pressure. If there was $>5 \mathrm{~mm} \mathrm{Hg}$ difference between any two readings, an additional reading was obtained, and then the average of these multiple readings was used. ${ }^{22}$

\section{Statistical analysis}

A pooled analysis was performed followed by the decision rule. The collected information was analyzed using SPSS version 15 . The analysis for quality of services was limited to the number of clinics which had the available facilities.

\section{Ethical clearance}

The ethical clearance for the study was granted by the Ethics committee of the University of Sri Jayewardenepura.

\section{Results}

Due to the lack of availability of the $\mathrm{MOH}$ in 12 $(21.8 \%)$ of the antenatal clinics, history, clinical examinations and the blood pressure measurements could not be performed in $60(21.8 \%)$ women (Table 1 and 2). A history was obtained in only 8 $(2.9 \%)$ women and a clinical examination with regards to diagnosis of $\mathrm{PIH} / \mathrm{PET}$ was performed in 48 (17.5\%) women (Table 2).

Quality of facilities was acceptable in all $\mathrm{MOH}$ areas other than for one $\mathrm{MOH}$ area which was substandard for facilities of a doctor. The quality of services was unacceptable in all $\mathrm{MOH}$ areas other than for two $\mathrm{MOH}$ areas which was acceptable for quality of blood pressure measurements and two other $\mathrm{MOH}$ areas which were acceptable for informing the results of the urine albumin. 
Table 1: Quality of facilities in diagnosis of PIH/PET and application of LQAS

\begin{tabular}{|l|c|c|c|}
\hline \multirow{2}{*}{$\begin{array}{l}\text { Quality of facilities in the antenatal clinic } \\
\text { (n=55 clinics) }\end{array}$} & \multicolumn{2}{|c|}{ Provision at clinics } & $\begin{array}{c}\text { MOH areas with } \\
\text { unacceptable } \\
\text { performances }\end{array}$ \\
\cline { 2 - 4 } & Not provided (\%) & Provided (\%) & 1 MOH area \\
\hline A MOH doctor & $12(21.8)$ & $43(78.2)$ & None \\
\hline Stethoscope & $4(7.3)$ & $51(92.7)$ & None \\
\hline Sphygmomanometer & $5(9.1)$ & $50(90.9)$ & None \\
\hline Facilities for investigation of urine Albumin & $4(7.3)$ & $51(92.7)$ & \\
\hline
\end{tabular}

Table 2: Quality of services in diagnosis of PIH/PET and application of LQAS

\begin{tabular}{|c|c|c|c|c|c|c|c|}
\hline \multirow{3}{*}{ Quality of services on risk assessment } & \multicolumn{4}{|c|}{ History and Examination } & \multirow{2}{*}{\multicolumn{2}{|c|}{ Total }} & \multirow{3}{*}{$\begin{array}{l}\text { MOH areas } \\
\text { with } \\
\text { unacceptable } \\
\text { performances }\end{array}$} \\
\hline & \multicolumn{2}{|c|}{ Not provided } & \multicolumn{2}{|c|}{ Provided } & & & \\
\hline & No & $\%$ & No & $\%$ & No & $\%$ & \\
\hline History taken & 207 & 96.3 & 8 & 3.7 & 215 & 100 & All \\
\hline \multicolumn{8}{|l|}{ Examination } \\
\hline Ankle edema/Swelling of hands/face & 167 & 77.8 & 48 & 22.3 & 215 & 100 & All \\
\hline BP measurement & 30 & 13.9 & 185 & 86.0 & 215 & 100 & $2 \mathrm{MOH}$ areas \\
\hline BP measured according to standards & 124 & 67.0 & 61 & 33.0 & 185 & 100 & All \\
\hline Informed the BP & 126 & 68.1 & 59 & 31.9 & 185 & 100 & All \\
\hline \multicolumn{8}{|l|}{ Investigation for urine Albumin } \\
\hline According to standards & 235 & 85.4 & 20 & 7.3 & 255 & 100 & All \\
\hline Informed results of investigation & 78 & 28.4 & 177 & 64.4 & 255 & 100 & $2 \mathrm{MOH}$ areas \\
\hline
\end{tabular}

Among the total number of women observed the blood pressure was measured according to standards in $22.2 \%$ and was informed to $21.5 \%$ of the pregnant women. The $\mathrm{BP}$ readings recorded on the pregnancy card was compared with results of the principal investigator. The pregnant women's systolic blood pressure (SBP) was categorized into '>120mmHg' and ' $\leq 120 \mathrm{mmHg}$ ' and the diastolic blood pressure (DBP) was categorized into '>80mmHg' and ' $\leq 80 \mathrm{mmHg}$ ' (Table 3 ). The precision rate of the women who were correctly diagnosed with SBP and DBP was 80\% (95\% CI: $72.2 \%-87.8 \%)$ and $33.3 \%$ (95\% CI: $24.3 \%-42.3 \%$ ) respectively. The sensitivity for SBP and DBP was $57.1 \%$ (95\% CI: $47.4 \%$ $66.8 \%$ ) and $16.7 \%$ (95\% CI: 9.4\% -24\%) respectively.

\section{Discussion}

To the best of our knowledge, this is the first study of quality on detection of PIH/PET at the field antenatal clinics in Sri Lanka where more than $98 \%$ of the pregnant women are registered. The quality of detection of $\mathrm{PIH} / \mathrm{PET}$ was assessed in terms of facilities, services

Table 3: Validity of blood pressure measurement

\begin{tabular}{|c|c|c|c|c|c|}
\hline \multirow{2}{*}{$\begin{array}{l}\text { BP measured by } \\
\text { the MOH } \\
\text { SBP }\end{array}$} & \multicolumn{2}{|c|}{ SBP/DBP measured by the PI } & \multirow{2}{*}{$\begin{array}{c}\text { Sensitivity } \\
\text { (95\% CI) }\end{array}$} & \multirow{2}{*}{$\begin{array}{l}\text { Specificity } \\
(95 \% \text { CI) }\end{array}$} & \multirow{2}{*}{$\begin{array}{l}\text { Positive predictive } \\
\text { value }(95 \% \mathrm{CI})\end{array}$} \\
\hline & $>120 \mathrm{mmHg}$ & $\leq 120$ & & & \\
\hline$>120 \mathrm{mmHg}$ & $8(80 \%)$ & $2(20 \%)$ & \multirow{2}{*}{$\begin{array}{c}57.1 \% \\
(47.4 \%-66.8 \%) \\
\end{array}$} & \multirow{2}{*}{$\begin{array}{c}97.7 \% \\
(94.8 \%-100 \%)\end{array}$} & \multirow{2}{*}{$\begin{array}{c}80 \% \\
(72.2 \%-87.8 \%) \\
\end{array}$} \\
\hline$\leq 120 \mathrm{mmHg}$ & $6(6.7 \%)$ & $84(93.3 \%)$ & & & \\
\hline DBP & $>80 \mathrm{mmHg}$ & $\leq 80 \mathrm{mmHg}$ & & & \\
\hline$>80 \mathrm{mmHg}$ & $1(33.3)$ & $2(66.7)$ & \multirow{2}{*}{$\begin{array}{c}16.7 \% \\
(9.4 \%-24 \%)\end{array}$} & \multirow{2}{*}{$\begin{array}{c}97.9 \% \\
(95.1 \%-100 \%)\end{array}$} & \multirow{2}{*}{$\begin{array}{c}33.3 \% \\
(24.3 \%-42.3 \%)\end{array}$} \\
\hline$\leq 80 \mathrm{mmHg}$ & $5(5.2)$ & $92(94.8)$ & & & \\
\hline
\end{tabular}

Keys: BP: blood pressure; MOH: Medical Officer of Health; PI: principal investigator; SBP: systolic blood pressure; DBP: diastolic blood pressure. and validity of the blood pressure measurements. PIH and post partum hemorrhage are the leading causes of maternal mortality in Sri Lanka for more than two decades. $^{4}$ Thus the outcome of the study was aimed at reducing the PIH specific maternal mortality in order to bring the maternal mortality of Sri Lanka to one digit.

This study clearly shows that the quality of facilities in the field antenatal clinics in the Colombo District was better than the quality of services. Among the indicators for quality of facilities, the presence of a doctor unacceptable in one area. Other than for the blood pressure being measured and informing if albumin was present in urine, the quality of services was unacceptable in all areas. Further the sensitivity for measuring the SBP and the DBP was low.

It is now known that with quality antenatal care with early detection would help reduce PIH specific maternal mortality ratio. The foremost feature in reducing mortality and morbidity due to PIH/PET would be to diagnose them. A systematic review shows that the risk of developing PIH was seven times more in a woman with past

South East Asia Journal of Public Health 2012;2(2):55-60. 
history of PET and three times more in a woman with a family history of PIH/ PET. ${ }^{23}$ A clinical history and examination was not taken in nearly $96 \%$ and $78 \%$ of the women, and in addition to this, the blood pressure was not measured in 90 of the 275 women observed. In toting up, the validity of blood pressure measurement was poor, which leads to a high non-detection rate of PIH/PET among the pregnant women attending the field antenatal clinics.

The findings of the study in Tanzania also reflect the quality of services in Sri Lanka. The healthcare workers had screened $65 \%$ of the pregnant women for hypertension, but had only informed the result of the BP measurement in $9 \%$ of the women. ${ }^{24}$ Another similar study in Nigeria reports that $44 \%$ of the pregnant women attending the antenatal clinics were not examined by the midwives for BP measurement. ${ }^{7}$ An overview of evidence of the effectiveness of antenatal care in relation to maternal mortality and serious morbidity conditions has shown that only a low proportion of risk factors are detected at antenatal clinics. ${ }^{25}$ In a survey of pregnant women in United Kingdom demonstrated that more than one third of women developed seizures in hospital with no documentation of hypertension nor proteinuria. ${ }^{26}$

The SBP and DBP measured by the healthcare workers showed low sensitivity due to three main deviations from the guidelines: not removing the tight clothing, having legs crossed and most specifically the inappropriate cuff size. ${ }^{22}$ A limitation in this study was that a stethoscope with two headsets was not used.

To prevent PET, quality of facilities and services on investigation of urine albumin is an utmost priority at a primary care level. It was observed that the urine in the test tube was boiled and acetic acid was added according to standards only in $8 \%$ of the investigations. Similar results were seen in a study by Gunathunga in 2000, in the western province of Sri Lanka. ${ }^{27}$ It was reported that the acetic acid was never added in $68.8 \%$ of the clinics.

A limitation for this study was that the cost was not considered. A cost-benefit study specifically targeted on the cost of detection of urine albuminuria in the field clinics using other feasible methods such as dipstick would have been an added advantage.

The LQAS was found to be advantageous in assessing the quality of care. Substandard care in unacceptable $\mathrm{MOH}$ areas should be targeted and urgent steps should be taken to improve the quality of care. As Sri Lanka is a country with low and limited resources, improving the technical competence of healthcare workers in diagnosing PIH/PET would help to increase the precision rate of detection.

This was an observational study, involving participatory observations. However the findings of the study are unlikely to have resulted from observer bias as the checklist used standards. ${ }^{28}$

However, even with this quality of facilities and services in the field antenatal clinics, Sri Lanka has a low mortality rate compared to other developing countries, albeit a higher rate when compared to developed countries. This could be due to the fact all pregnant women $(100 \%)$ who had abnormal clinical findings $(n=13)$ had been referred to a tertiary institution.

\section{Conclusion}

It has been seen in the past that the maternal mortality of Sri Lanka is declining. However further decline in deaths is a necessity to help to move the maternal mortality rate of Sri Lanka towards a single digit. PIH/PET has been one of the most common causes of deaths in the past two decades. The study brings out the quality of facilities and services in diagnosing PIH/PET in the field antenatal clinics in Sri Lanka.

The need for quality improvement in diagnosing PIH/ PET is evident at the field antenatal clinics in the Colombo district. The quality of facilities was unacceptable in one area. The quality of services was unacceptable in all areas for history taking and examination and investigation for urine albumin. Further the sensitivity for measuring the SBP and DBP was low. For a substantial improvement continuous professional education or training for healthcare workers could enhance the technical competence of the health care personnel. This could be further supported by training on communication skills and counseling for diagnosis of PIH/PET, which would help reduce one of the leading causes of maternal deaths, helping Sri Lanka to reduce maternal mortality rate.

\section{Acknowledgement}

We thank the Swedish Agency for Research and Cooperation with Developing Countries (SAREC) for the funds provided.

\section{References}

1. Shah MR. Hypertensive disorders in pregnancy. $1^{\text {st }}$ ed. New Delhi: Jaypee Brothers Medical Publishers (P) Ltd., 2007.

2. Fernando D, Jayatilleka A, Karunaratna V. Pregnancy-reducing maternal deaths and disability in Sri Lanka: National strategies. Br Med Bull 2003;67:85-98.

3. Attygalle D. Maternal Mortality in Sri Lanka: towards a single digit. JCCPSL 2011;16;:31-37.

4. Attygalle D, Tillekeratan A. Overview of maternal mortality in Sri Lanka 2001-2005. Colombo: Family Health Bureau, 2009.

5. Family Health Bureau. National Statistics. 2009. http://www.familyhealth.gov.lk/web/index.php? option $=$ com content\&view $=$ article\&id $=134 \&$ Itemid=74\&lang=en $\quad$ (accessed Nov 
2012).

6. Khan KS, Wojdyla D, Say L, Gulmezoglu AM, Van Look PF. WHO analysis of causes of maternal death: a systematic review. Lancet 2006;367:1066-74.

7. Prual A, Toure A, Huguet D, Laurent Y. The quality of risk factor screening during antenatal consultations in Niger. Health Policy Plan 2000;15:11-6.

8. Cuevas P, Fraser W, Reyes HRD, Reinharz D, Daftari A, Heinz CS, et al. Critical pathways for the management of preeclampsia and severe preeclampsia in institutionalized health care settings. BMC Pregnancy Childbirth 2003;3(6).

9. De Brouwere V, Lerberghe WV. Safe Motherhood Strategies: A review of the evidence. HSO\&P 2001;17.

10. Mohamed AM, Kishk NA, Shokeir NF, Kassem MS. Role of antenatal care in toxemia of pregnancy in alexandria. $J$ Egypt Public Health Assoc 2006;81:1-28.

11. Haeman MI, Gupton AL, Moffatt ME. Prevalence and predictors of inadequate antenatal care: a comparison of aboriginal and non-aboriginal women in Manitoba. J Obstet Gynaecol Can 2005;27:237-46.

12. Chesley LC, Sibai BM. Blood pressure in the midtrimester and future eclampsia. Am J Obstet Gynecol 1987;157:1258-61.

13. Donabedian A. Quality of care: problems of measurement. II. Some issues in evaluating the quality of nursing care. Am J Public Health Nations Health 1969;59:1833-6.

14. Bhuiya A, Hanifi SM, Roy N, Streatfield PK. Performance of the lot quality assurance sampling method compared to surveillance for identifying inadequately-performing areas in Matlab, Bangladesh. J Health Popul Nutr 2007;25:37-46.

15. Lwanga SK, Lemeshow S. Sample Size Determination in health studies: A practical manual. Geneva: World Health Organization, 1991.

16. Kielmann AA, Janowski K, Annett H. Assessing district health needs, services and systems: Protocols for rapid data collection and analysis. London and Basingstoke: Macmillan, AMREF, 1992.

17. UNICEF, WHO, UNFPA. Guidelines for monitoring the availability and use of obstetric services. New York: UNICEF, 1997.
18. Valadez JJ, Devkota BR. Decentralized supervision of community health programs: using LQAS in two districts of southern Nepal. Boston: Management Sciences for Health, 2002

19. Prathapan S, Fonseka P, Lindmark G, Lokubalasooriya A. Quality of antenatal care in the Colombo District. Colombo: Post Graduate Institute of Medicine, 2009.

20. Milne F, Redman C, Walker J, Baker P, Bradley $\mathrm{J}$, Cooper $\mathrm{C}$, et al. The pre-eclampsia community guideline (PRECOG): how to screen for and detect onset of pre-eclampsia in the community. BMJ 2005;330:576-80.

21. National Collaborating Centre for Women's and Children's Health (UK). Antenatal Care: Routine Care for the Healthy Pregnant Woman. London: RCOG Press, 2008.

22. Pickering TG, Hall JE, Appel LJ, Falkner BE, Graves J, Hill MN, et al. Recommendations for blood pressure measurement in humans and experimental animals. Part 1: Blood pressure measurement in humans. A statement for professionals from the Subcommittee of Professional and Public Education of the American Heart Association Council on High Blood Pressure Research. Circulation 2005;111:697-716.

23. Duckitt K, Harrington D. Risk factors for preeclampsia at antenatal booking: systematic review of controlled studies. BMJ 2005;330:565.

24. Urassa DP, Nystrom L, Carlstedt A, Msamanga GI, Lindmark G. Management of hypertension in pregnancy as a quality indicator of antenatal care in rural Tanzania. Afr J Reprod Health 2003;7:69 $-76$.

25. Carroli G, Rooney C, Villar J. How effective is antenatal care in preventing maternal mortality and serious morbidity? An overview of the evidence. Paediatr Perinat Epidemiol 2001;15 (Suppl 1):1-42.

26. Douglas KA, Redman CW. Eclampsia in the United Kingdom. BMJ 1994;309:1395-400.

27. Gunathunga W, Fernando DN. Assessment of community maternal care performance of public health midwives of a province in Sri Lanka: a multi-method approach. Southeast Asian J Trop Med Public Health 2000;31:310-8.

28. Bailey L, Vardulaki K, Langham J, Chandramohan D. Introduction to Epidemiology. London: Open University Press in collaboration with LSHTM, 2006. 